Elsevier Editorial System(tm) for The International Journal of Biochemistry \& Cell Biology

$$
\text { Manuscript Draft }
$$

Manuscript Number: BC-D-08-00524R1

Title: Regulation of podoplanin/PA2.26 antigen expression in tumour cells. Involvement of calpainmediated proteolysis

Article Type: Full Length Article

Keywords: transmembrane mucin; alternative splicing; alternative polyadenylation; posttranslational regulation

Corresponding Author: Dr. Jaime Renart,

Corresponding Author's Institution: Instituto de Investigaciones Biomedicas

First Author: Ester Martín-Villar, PhD

Order of Authors: Ester Martín-Villar, PhD; María M Yurrita; Beatriz Fernández-Muñoz; Miguel Quintanilla, PhD; Jaime Renart, PhD

Manuscript Region of Origin: SPAIN

Suggested Reviewers: 


\section{Regulation of podoplanin/PA2.26 antigen expression in tumour cells. Involvement} of calpain-mediated proteolysis

Ester Martín-Villar, María M. Yurrita, Beatriz Fernández-Muñoz, Miguel Quintanilla and Jaime Renart*

Instituto de Investigaciones Biomédicas Alberto Sols, CSIC-

UAM Arturo Duperier, 4, 28029-Madrid. Spain

*Corresponding author:

Jaime Renart

Instituto de Investigaciones Biomédicas Alberto Sols, CSIC-

UAM Arturo Duperier, 4, 28029-Madrid. Spain

Tel: +34915854439

Fax: +34915854 401

E-mail: jrenart@,iib.uam.es

Running title: Regulation of podoplanin/PA2.26 antigen expression

Abbreviations: ALLN, N-acetyl-L-Leucyl-L-Leucyl-L-Norleucinal; EMT, epithelial mesenchymal transition; PDPN, podoplanin; RACE, rapid amplification of cDNA ends; UTR, untranslated region; RT-PCR, reverse transcription coupled to polymerase chain reaction.

Keywords: transmembrane mucin; alternative splicing; alternative polyadenylation; posttranslational regulation 


\section{Abstract}

Podoplanin/PA2.26 antigen is a small transmembrane mucin expressed in different types of cancer where it is associated with increased cell migration, invasiveness and metastasis. Little is known about the mechanisms that control podoplanin expression. Here, we show that podoplanin synthesis can be controlled at different levels. We analyzed podoplanin expression in a wide panel of tumour cell lines. The podoplanin gene $(P D P N)$ is transcribed in cells derived from sarcomas, embryonal carcinomas, squamous cell carcinomas and endometrial tumours, while cell lines derived from colon, pancreatic, ovarian and ductal breast carcinomas do not express $P D P N$ transcripts. $P D P N$ is expressed as two mRNAs of $\sim 2.7$ and $\sim 0.9 \mathrm{~kb}$, both of which contain the coding sequence and arise by alternative polyadenylation. Strikingly, in most of the cell lines where $P D P N$ transcripts were found, no podoplanin or only very low levels of the protein could be detected in Western blot.

Treatment of several of these cell lines with the calpain inhibitor calpeptin resulted in podoplanin accumulation, whereas lactacystin, a specific inhibitor of the proteasome, had no effect. In vitro experiments show that podoplanin is a substrate of calpain-1. These results indicate that at least in some tumour cells absence or reduced podoplanin protein levels are due to post-translational calpain-mediated proteolysis. We also report in this article the identification of a novel podoplanin isoform that originates by alternative splicing and differs from the standard form in lacking two cytoplasmic residues (YS). YS dipeptide is highly conserved across species, suggesting that it might be functionally relevant.

\section{Introduction}

Podoplanin is a small mucin-like transmembrane protein originally identified as a 
marker of glomerular epithelial (podocyte) cells (Breiteneder-Geleff et al., 1997; Breiteneder-Geleff et al., 1999). It was also characterized in distinct biological contexts under a variety of names. For example: as T1 $\alpha$, a marker for alveolar epithelial cells (Rishi et al., 1995); as PA2.26, a cell-surface antigen induced in epidermal keratinocytes during wound healing and chemical carcinogenesis (Gandarillas et al., 1997; Scholl et al., 1999); as gp40/gp36, a main receptor for the influenza C virus (Zimmer et al., 1995; Zimmer et al., 1999); and as Aggrus, a platelet aggregation-inducing glycoprotein expressed on the surface of tumour cells (Kato et al., 2003). The interest in this membrane glycoprotein has increased over the years due to several reasons. First, it is a specific marker for the lymphatic endothelium (Breiteneder-Geleff et al., 1999). Second, podoplanin null mice die at birth due to malformation of alveoli (Ramirez et al., 2003). These mice also show defects in the lymphatic vascular system (Schacht et al., 2003). Third, podoplanin expression is up-regulated in a variety of human cancers, including testicular germ cell tumours (Schacht et al., 2005; Kato et al., 2005), mesotheliomas (Chu et al., 2005) and different types of carcinomas (Kato et al., 2003; Kato et al., 2005; Martin-Villar et al., 2005; Schacht et al., 2005; Wicki et al., 2006).

Several data indicates that podoplanin plays an important role in malignant progression (reviewed in Wicki and Christofori, 2007). Kato and co-workers have proposed a prometastatic function for podoplanin based on its ability to induce platelet aggregation associated with the development of arrested tumour emboli (Kato et al., 2004). Moreover, we have demonstrated that podoplanin can promote an epithelial to mesenchymal transition (EMT) associated with increased cell migration, invasion and metasasis (Martín-Villar et al., 2006; Ramirez et al., 2003; Scholl et al., 2000; Scholl et al., 1999). This phenotypic conversion depends on the binding of the cytoskeletal-membrane linker ezrin to the cytoplasmic domain of podoplanin, which 
leads to the activation of RhoA GTPase (Martín-Villar et al., 2006). Nevertheless, other studies have shown that podoplanin destabilizes cell-to-cell adhesion and promotes cell migration without inducing EMT (Martin-Villar et al., 2005; Wicki et al., 2006).

Due to its role in tumour progression the regulation of podoplanin expression is of great interest. Several cDNA sequences encoding an identical 162-amino acids human podoplanin polypeptide have been reported by us and others (Ma et al., 1998; Zimmer et al., 1999; Martin-Villar et al., 2005). Comparison of these sequences with genomic data bases predicts 6 exons and 5 introns within the PDPN gene locus (MartinVillar et al., 2005). The first exon contains a 5' UTR of about $203 \mathrm{nt}$ before the ATG initiation codon. The last exon contains the termination codon followed by a long UTR of $1769 \mathrm{nt}$ which includes a $200 \mathrm{nt}$ AluSc sequence in the reverse orientation at the 3' end. The $P D P N$ gene is transcribed into two mRNAs of about $2.7 \mathrm{~kb}$ and $0.9 \mathrm{~kb}$ in normal human tissues (Kriehuber et al., 2001; Martin-Villar et al., 2005). While the larger transcript fits the $2737 \mathrm{nt}$ size reported by us for the $P D P N$ cDNA sequence (Martin-Villar et al., 2005), the origin of the $0.9 \mathrm{~kb}$ was unknown until now.

In this article, we show that podoplanin expression is regulated by a number of mechanisms. First, alternative polyadenylation signals account for the two $2.7 \mathrm{~kb}$ and $0.9 \mathrm{~kb} P D P N$ transcripts expressed in normal tissues and cell lines. Second, an alternative splicing mechanism gives rise to a $P D P N$ mRNA form encoding a shorter (160-amino acids) protein lacking two residues at the C-terminus. Third, in several human cell lines podoplanin protein expression is downregulated by proteolytic degradation mediated by calpain.

\section{Materials and methods}

\subsection{Cell culture}

Cell lines were grown in DMEM supplemented with 10\% FBS, 1 unit/ml 
penicillin, $0.1 \mathrm{mg} / \mathrm{ml}$ streptomycin, and $2 \mathrm{mM}$ L-glutamine. The neuroblastoma cell line SHSY5Y and the embryonal carcinoma cell line NCCIT were cultured in RPMI medium with $15 \%$ FBS.

MCF10A cells were cultured in DMEM:F12 (1:1), supplemented with 10\% goat serum, $10 \mu \mathrm{g} / \mathrm{ml}$ insulin, $20 \mathrm{ng} / \mathrm{ml}$ EGF, $0.5 \mu \mathrm{g} / \mathrm{ml}$ hydrocortisone, and $0.1 \mu \mathrm{g} / \mathrm{ml}$ cholera toxin. NIHOVCAR-3 cells were grown in DMEM with 10\% FBS. All cells were routinely cultured in $5 \% \mathrm{CO}_{2}$ at $37^{\circ} \mathrm{C}$. Pancreatic carcinoma cell lines (IMIMPC-1, IMIM-PC-2, Panc-1, SKPC-1 and RWP-1), were kindly provided by Dr. F.X. Real (Institut Municipal d'Investigacio Medica, Barcelona, Spain); human breast (MCF-7, MDA-MB-231, MDA-MB-435, BT-549 and CAMA-1), ovarian (NIHOVCAR and SKOV3) and endometrial (KLE, HEC1B, AN3Ca, HEC-265, Ishikawa, SK-UT1 and SK-UT1B) carcinoma cell lines by Drs. D. Sarrió and G. Moreno-Bueno (Centro Nacional de Investigaciones Oncológicas, Madrid, Spain); embryonal carcinoma cell lines (NCCIT and NTERA-2) by Dr. M.P. de Miguel (Cell Engineering Laboratory, Hospital Universitario La Paz, Madrid, Spain); and squamous cell carcinoma cell lines HN1 9 and HN30 by Dr. S Gutkind (National Institute of Dental and Craniofacial Research, NIH, Bethesda, USA).

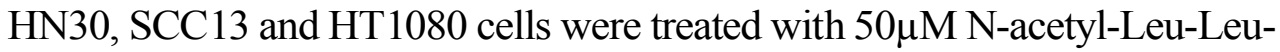
Norleu-al (ALLN) (Calbiochem) and 10 $\mu$ M MG132 (Calbiochem) to inhibit both the proteasome and calpain proteolytic activities. To inhibit specifically either the proteasome or calpain function, cells were treated with $10 \mu \mathrm{M}$ Lactacystin or $50 \mu \mathrm{M}$ calpeptin (Calbiochem), respectively. The inhibitors were dissolved in dimethylsulfoxide (DMSO) and cells treated with vehicle only were also included as controls. After $14 \mathrm{~h}$ of incubation, cell lysates were obtained in RIPA buffer $(0.1 \%$ SDS, $0.5 \%$ sodium deoxycholate, $1 \% \mathrm{NP}-40,150 \mathrm{mM} \mathrm{NaCl}, 50 \mathrm{mM}$ Tris- $\mathrm{HCl} \mathrm{pH}$ 
7.5) and a cocktail of protease inhibitors and analysed by Western blotting.

\subsection{Western blot analysis and antibodies}

Cell lysates were obtained in RIPA buffer and analyzed by western blotting after electrophoresis in 10\% SDS-PAGE, as described previously (Martin-Villar et al., 2005). Two different anti-human podoplanin antibodies were used. Ab1 is a polyclonal antibody against a synthetic peptide comprising amino acids $37-51\left(\mathrm{P}_{37-51}\right)$ of the human podoplanin ectodomain (Martin-Villar et al., 2005), and Ab2 is a polyclonal anti-human podoplanin antibody against the entire podoplanin ectodomain purchased from Cell Sciences. Ab1 and Ab2 were used at a dilution of 1:8000 and at $1 \mu \mathrm{g} / \mathrm{ml}$, respectively. As a control, Ab1 was preincubated with an excess of either $P_{37-51}(3 \mu \mathrm{g} / \mathrm{ml})$ or an unrelated peptide, for $30 \mathrm{~min}$, in order to verify the specificity of recognition (MartinVillar et al., 2005). Antibodies for $\alpha$-tubulin (DM1A) and $\alpha$-actin (both from SigmaAldrich) were used at 1:10 000 dilution; antibodies for Smad2/3 (Cell Signaling) and $\beta$ catenin (BD Biosciences) were used at 1:1000 and 1:100, respectively, and antibody

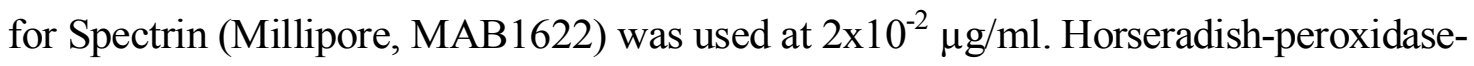
conjugated sheep anti-mouse (Amersham Biosciences) and goat antirabbit (Biosciences) IgGs were used as secondary antibodies.

\subsection{In vitro digestion with calpain-1}

NCCIT and MDCK-PDPN-EGFP (Martín-Villar et al., 2006) cells were lysed with RIPA buffer containing $1 \mathrm{mM}$ EDTA, $1 \mathrm{mM}$ EGTA, $1 \mathrm{mM}$ PMSF, $10 \mu \mathrm{g} / \mathrm{ml}$ aprotinin and $10 \mu \mathrm{g} / \mathrm{ml}$ pepstatin. Extracts were centrifuged at $14000 \mathrm{rpm}$ for $15 \mathrm{~min}$. Reaction mixtures containing $50 \mathrm{mM}$ TrisCl, $\mathrm{pH}$ 7.5, $5 \mathrm{mM}$ DTT, $2.5 \mathrm{mM} \mathrm{CaCl}_{2}$ and $30 \mu \mathrm{g}$ of protein., were digested with various amounts of calpain-1 (Calbiochem), as shown in Fig. 5C. Digestions were carried out for $30 \mathrm{~min}$ at $37^{\circ} \mathrm{C}$ and analysed by western blotting. 


\subsection{Northern-blot and RT-PCR analysis}

$70-80 \%$ confluent cells were used to obtain total RNA with the Rneasy (Qiagen) kits. Twenty $\mu \mathrm{g}$ of total RNA from different cells lines were electrophoresed in $1 \%$ agarose gels with $0.41 \mathrm{M}$ formaldehyde and transferred downwards with 10xSSC as described (Chomczynski and Mackey, 1994). Hybridization was done with $10^{6}$ $\mathrm{cpm} / \mathrm{ml}$ of ${ }^{32} \mathrm{P}$-labeled PDPN cDNA (Martin-Villar et al., 2005) using the conditions of Church and Gilbert .

Reverse transcription was performed at $37^{\circ} \mathrm{C}$ for 2 hours using the enzyme from avian myeloblastosis virus (Promega), $2 \mu \mathrm{g}$ of total RNA extracted from the cell lines, and random hexadeoxynucleotides as primers. The products of the reaction were used for PCR (30 cycles: $94^{\circ} \mathrm{C}$ for 1 minute, $59^{\circ} \mathrm{C}$ for 1 minute 30 seconds, and $72^{\circ} \mathrm{C}$ for 1 minute 30 seconds) in a Gene Amp PCR system 2400 (Perkin Elmer, Foster City, CA). For human podoplanin amplification the following oligonucleotides were used: 5'- CGGGAACGATGTGGAAGGTGTCA (forward) and 5'GGGACAGGGCACAGAGTCAGAAAC (reverse). Oligonucleotides for glyceraldehyde3 - phosphate dehydrogenase (GAPDH) amplification have been described elsewhere (Scholl et al., 2000).

\subsection{Determination of the Origin of Transcription}

Primer extension was done with oligodeoxynucleotides 5'GGAAAATTAAAAAGCACCGCGGCCACAG (positions -57 to -84 from the initiation codon) and 5'-GTTGAGTTGTTGCTCTCCTGGGGGCCGAGC (positions -8 to -37 from the initiation codon). Oligodesoxynucleotides $(10 \mathrm{pmol})$ were labelled with $50 \mu \mathrm{Ci}\left[\gamma^{32} \mathrm{P}\right] \mathrm{ATP}$ using polynucleotide kinase as described by Sambrok and Russell . The primer extension reaction was carried out with $15 \mu \mathrm{g}$ of NCCIT total RNA. Annealing, reverse transcription and electrophoresis of the products in $6 \%$ 
acrylamide gels in the presence of 7M urea was essentially done as described (Sambrook and Russell, 2001).

\subsection{3'-RACE}

To characterize polyadenylation sites, we used total RNA from NCCIT or NTERA 2 cells and normal human lung tissue (Tumour Tissue Bank of the Hospital Universitario La Paz, Madrid) because podoplanin is normally expressed in this tissue (Martin-Villar et al., 2005). Fifteen $\mu$ g of RNA was used for first strand cDNA synthesis using MMLV Reverse Transcriptase (Promega) and random hexadeoxynucleotides as primers, in a $20 \mu$ volume reaction according to the manufacturer's instructions. One $\mu$ l of these reactions was used for a first PCR using primer 6972-F (5'- CACACAGACAACAGTTGAGAA, bases 348-3 68 from the initiator ATG) and oligo(dT)- M13D (5'-

CATGTTGTAAAACGACGGCCAG(T)24), with the following amplification scheme: $94^{\circ} \mathrm{C}$ for $3 \mathrm{~min}, 30$ cycles of $94^{\circ} \mathrm{C}$ for $50 \mathrm{sec}, 48^{\circ} \mathrm{C}$ for $50 \mathrm{sec}$ and $72^{\circ} \mathrm{C}$ for 90 sec, followed by $72^{\circ} \mathrm{C}$ for $7 \mathrm{~min}$. The reaction mixture $(50 \mu \mathrm{l})$ contained 1 unit of Tth DNA polymerase (BioTools, Madrid, Spain), $1 \mu \mathrm{M}$ primers and $0.2 \mathrm{mM}$ dNTPs. One $\mu l$ of the first PCR reactions were amplified again with INT-F primer (5'-

CAATCATCGTTGTGGTTATGC, bases 440-460 from the initiator ATG) and M13 universal direct primer using the same amplification protocol. PCR products were ligated to pGEM-Teasy vector (Promega) overnight at $16^{\circ} \mathrm{C}$ and plated on 100 $\mu \mathrm{g} / \mathrm{ml}$ ampicilin agar plates. Positive colonies were detected by colony PCR with M1 3 direct and reverse universal primers in a $20 \mu \mathrm{l}$ reaction volume using the above conditions. Ten $\mu$ l of the reactions were electrophoresed in $1 \%$ agarose gels; the remaining volume was diluted five fold with water and $7 \mu 1$ of the dilution sequenced with the M13-R universal primer in an ABI 377 sequencer. 
To study the distal polyadenylation site we carried out the first PCR with oligonucleotide DISTAL- 1 -F (5' -GAAACCAAGAGCCAGTTGTCC, positions 1 617-1 637) instead of 6972-F, and the second PCR with DISTAL-3-F (5'CATATTTGAACACCAGCTGATTGAGAGAAGG, positions 2 459-2 489).

\subsection{Sucrose gradient fractionation of polysomes}

Sucrose gradient fractionation was performed essentially as described by del Prete et al. Fractions were collected from the top, digested with proteinase $\mathrm{K}$ and extracted with phenol:chloroform. RNA was recovered by ethanol precipitation and analysed by Northern blotting as described above.

\subsection{Confocal immunofluorescence analysis}

Immunofluorescence detection of human podoplanin in KLE cells was performed on cells fixed with $3.7 \%$ formaldehyde in PBS, permeabilized with $0.05 \%$ Triton X-100. The podoplanin polyclonal antibody Ab1 was used at 1:500 dilution. Alexa-488-labeled antirabbit (Molecular Probes) IgG was used as secondary antibody. Staining of nuclei was performed in a solution of 4',6-diamino-2-phenilindole (DAPI, $1 \mu \mathrm{g} / \mathrm{ml}$; SigmaAldrich). Confocal laser scanning microscopy was performed in a Leica TCS-SP2 microscope (Leica Microsystems, Heidelberg GmbH). Images were taken using a 63x oil (NA 1.32) immersion objective and assembled using Leica Confocal Software 2.0.

\section{Results and discussion}

\subsection{Podoplanin expression in human cell lines}

The expression of podoplanin was analyzed in a wide panel of human normal and tumour cell lines by RT-PCR and Western immunoblotting (Fig. 1 and Table 1). While no expression was found in cell lines derived from colorectal (4/4), pancreatic (5/5), breast (5/5) and ovarian (2/2) carcinomas, significant levels of PDPN 
transcripts were observed in cultured cells derived from sarcomas (2/2), embryonal carcinomas (2/2), squamous cell carcinomas (6/7), prostate carcinoma $(1 / 1)$ and endometrial tumours (3/7). PDPN mRNA expression was also detected in several nontumour cell lines (Fig. 1A, Table 1). In the $P D P N$-expressing cell lines, Northern blot analysis revealed the presence of two mRNA species of about 2.7 and $0.9 \mathrm{~kb}$ (Fig. 1B), as previously reported for normal tissues (Kriehuber et al., 2001; Martin-Villar et al., 2005). Interestingly, in many of the cell lines expressing $P D P N$ transcripts, very low levels or a complete absence of protein was found by Western blot analysis (Fig. 1C and Table 1). In fact, only 2 cell lines out of 17 containing transcripts had high levels of podoplanin protein: KLE, NCCIT (derived from a germ cell tumour and an endometrial carcinoma, respectively). For Western blot studies we used two distinct antibodies that specifically recognize the podoplanin ectodomain, as described in Materials and methods. Overall, there was a good correlation between the results obtained with both antibodies, ruling out the possibility that unsuccessful protein detection in cell lines expressing $P D P N$ transcripts was due to the antibody. A broad band of 35-50 kDa was found in the blot of NCCIT cells (Fig. 1C), likely indicating a highly heterogeneous pattern of protein glycosylation (Marks et al., 1999; MartinVillar et al., 2005) and/or different states of processing (see below). Confocal immunofluorescence analysis showed that podoplanin was concentrated at the cell surface on plasma membrane protrusions (Fig. 1D), as previously described (Martín-Villar et al., 2006; Martin-Villar et al., 2005; Scholl et al., 1999).

\subsection{Transcriptional heterogeneity of podoplanin}

Analysis of NCBI PDPN cDNA sequences revealed the presence of several ESTs compatible with the existence of multiple transcription start sites (MartinVillar et al., 2005), a fact recently confirmed by others (Hantusch et al., 2007). We 
used primer-extension analysis to map the start site(s) for $P D P N$ gene transcription in NCCIT cells (Fig. 2A). The major transcription start site (designated +1 ) was located 94 bp 5' upstream from the ATG start codon. This site differs from that reported by Hantusch and colleagues in MG63 osteosarcoma cells, in which most transcription initiates at a position $107 \mathrm{bp}$ upstream from the site determined by us. Thus, transcription initiation of $P D P N$ gene can take place over at least a $\sim 100 \mathrm{bp}$ region, a typical situation in TATA-less and CpG-island enriched promoters (Sandelin et al., 2007). We have cloned $2070 \mathrm{bp}$ of the 5' flanking region and performed reporter gene assays by introducing targeted deletions in the sequence. Our results were essentially similar to those reported before (Hantusch et al., 2007), showing that the 5' flanking region contains motifs that provide basic podoplanin activity and that silencing motifs are located in a $300 \mathrm{bp}$ region located $700 \mathrm{bp}$ upstream the ATG start codon (data not shown).

While the larger $P D P N$ transcript of $\sim 2.7 \mathrm{~kb}$ fits the estimated size of the reported full-length podoplanin mRNA (Martin-Villar et al., 2005), the shorter mRNA species of $\sim 0.9 \mathrm{~kb}$ could represent an alternatively polyadenylated form. In order to test this possibility, we performed Northern blot analysis with RNA isolated from the cell lines HEK-293T and NTERA-2 using probes containing either the coding sequence (A), or most of the 3'-UTR (from positions 989 to 2 152, B) (Fig. 2B, upper panel). While probe A detected both mRNAs, probe B only recognized the larger transcript (Fig. 2B, lower panel), indicating that the $0.9-\mathrm{kb}$ transcript ends before or immediately after position 989 . To define the exact sites of polyadenylation of both mRNAs, we conducted 3'-RACE experiments (using 52 clones obtained from lung RNA and 4 clones from NCCIT cells RNA). Fig. 2C shows the sequence around the polyadenylation site for the short (upper sequence) and long (lower sequence) mRNA 
species. It is noteworthy that the proximal polyadenylation signal is not the canonical one, and has not been described before (Hu et al., 2005). We have denoted the proximal polyadenylation signal as ATTAYA because we found $\mathrm{T}$ in the fifth position in the lung but $\mathrm{C}$ in the NCCIT clones.

Polyadenylation of mRNAs requires the binding of at least two trans-acting factors: the Cleavage and Polyadenylation Specificity Factor (CPSF) that binds the Polyadenylation Signal (PAS), and the Cleavage Stimulation Factor (CstF), which interacts with U- and U/Grich elements downstream the polyadenylation site (Chen and Wilusz, 1998). However, auxiliary upstream elements (AUE) have been described in a variety of systems (Hu et al., 2005). Using the PolyA_DB2 server (Lee et al., 2007) several putative elements can be detected in both PDPN mRNA termini, either upstream or downstream of the polyadenylation site. It is interesting to note that strong AUEs are found in the small PDPN mRNA. One of them, AUUUGUAAC, is identical to that found in the SV40 late polyadenylation signal (Schek et al., 1992) and is not present in the large $P D P N$ mRNA. Similar sequences have been described in other systems (Hall-Pogar et al., 2005; Natalizio et al., 2002), located up to $60 \mathrm{nt}$ before the polyadenylation site. The fact that the distal polyadenylation site lacks this efficiency element could be the explanation for the approximate near similar proportion of both mRNAs expressed in tissues and cell lines, as the strength of the distal versus the proximal PAS could be balanced by the presence of strong AUEs upstream the proximal polyadenylation site.

\subsection{Identification of a novel podoplanin isoform arising by alternative splicing}

During the 3'-RACE analysis described above, we observed the presence of an additional transcriptional variant indicative of an alternate spliced podoplanin form (PDPN $\triangle Y$ Y). Both podoplanin isoforms share the extracellular and transmembrane 
domains, but the PDPN- $\Delta$ YS form lacks two residues (YS) from the cytoplasmic tail (Fig. 3A). Although the cDNAs derived from the 3' RACE analysis showed an equal frequency of occurrence for the standard and $\Delta \mathrm{YS}$ isoforms in our samples (lung and NCCIT cells), human EST databases predict a higher frequency of the standard isoform (Fig. 3B). This difference could be explained by the limited number of sequences analyzed in this article. Interestingly, the mouse $P d p n$ gene contains the same donor/acceptor sites in the boundary between exon 5 and intron 5 that would give rise to a similar variant lacking two residues (FS) of the endodomain. However, such a podoplanin form is not recorded in mouse databases, and we have been unable to detect it by 3' RACE experiments using different mouse tissues (data not shown). In this regard, it is interesting to note that recent results show a low conservation of alternative spliced forms between humans and mice (Takeda et al., 2008). The functional relevance of the human podoplanin $\triangle \mathrm{YS}$ isoform is unknown at present. The two amino acids YS are highly conserved across species from fishes to primates, with the exception of mice and rats in which phenyalanine substitutes tyrosine (Fig. 3C), although another rodent, Chinese hamster, has tyrosine instead of phenylalanine in this position. The strong conservation of these two amino acids suggests they might play an important role in the biology of podoplanin. Moreover, a recent study describes a number of genes, including $P D P N$, that appear to have alternative spliced formsdifferentially expressed in lung adenocarcinomas and normal tissue (Xi et al., 2008).

\subsection{Podoplanin stability is post-translationally regulated by calpain}

To ascertain whether the lack of podoplanin protein in cell lines that contained $P D P N$ transcripts was due to a post-translational mechanism, we studied the association of $P D P N \mathrm{mRNAs}$ with polysomes, an indication that mRNAs are being 
translated (Pradet-Balade et al., 2001; Qin et al., 2007). A representative analysis is shown in Fig. 4, showing that both $P D P N$ mRNAs are being translated.

The fact that $P D P N$ mRNAs are bound to the polysomal fractions is a strong indication that podoplanin is being translated. We hypothesized then, that podoplanin, once synthesized is being degraded. Since the proteasome is the main pathway for protein degradation in eukaryotic cells, we treated HN30, SCC13 and HT1080 cells with different proteasome inhibitors. Fig. 5A shows a representative experiment with HN30 cells. ALLN and MG132, but not lactacystin allowed the accumulation of podoplanin. As ALLN and MG132 are also inhibitors of calpain (Figueiredo-Pereira et al., 1994; Tsubuki et al., 1996), we treated cells with calpeptin, a specific inhibitor of calpains. As shown in Figs. 5A and B, calpeptin also allows podoplanin accumulation in all the cell lines tested, although with different efficiencies. In these assays we also monitored the accumulation of $\beta$ catenin and Smad2, two proteins known to be degraded by the proteasome(Massague et al., 2005; Moon, 2005) as a control of proteasomal activity. Taken together, the above results indicate that calpain-mediated proteolysis could be an important pathway to regulate podoplanin turnover in certain types of tumour cells.

To analyze whether podoplanin is indeed a direct substrate of calpain NCCIT and MDCK-PDPN-EGFP extracts were treated with increasing amounts of calpain1. As shown in Fig. 5C, calpain-1 was able to partially proteolyze podoplanin producing the accumulation of smaller fragments. As a control, spectrin, a well known calpain substrate was found to be proteolyzed in the same assay.

Structural and sequential determinants for substrates of calpain are not well defined, although PEST sequences (sequences rich in Pro, Glu/Asp and Ser/Thr 
residues, see Rechsteiner and Rogers, 1996) could be involved. In this regard, podoplanin has a moderate PEST sequence between positions 79 to 91 , as deduced by the PESTfind server (http://www.at.embnet.org/toolbox/pestfind). In addition to this sequence preference, calpain cleavage sites appear to be located in disordered segments of its substrate (Tompa et al., 2004).

Calpains are involved in a variety of physiological and pathological processes including cell attachment, spreading and migration(see Franco and Huttenlocher, 2005; and Lebart and Benyamin, 2006 for recent reviews). Podoplanin is known to promote surface protrusions (Martin-Villar et al., 2005; Wicki et al., 2006) and it has been also detected in the tail of migrating cells during contraction and detachment of the rear (Martín-Villar et al., 2006). The rationale for calpain-mediated proteolysis of podoplanin, as occur with other proteins involved in cell motility, could be to ensure proper timing and localization of highly dynamic multi-molecular complexes in order to be continually regulated.

In conclusion, we detect a variety of regulatory mechanisms for podoplanin expression, both transcriptional (multiple initiation sites, alternative splicing and polyadenylation) and post-translational (proteolytic processing). An important question now is to understand the different cell-specific events we detect, like the presence or absence of $P D P N$ mRNA or protein in the cells. It is likely that this calpain-mediated proteolytic processing observed in cell lines also takes place in normal and/or tumoural tissue. Therefore, caution should be taken in the analysis of podoplanin expression in gene profiling studies in primary tumours, as podoplanin protein determination may show different patterns of those found for mRNA. 


\section{Acknowledgements}

We thank Dr. D. Sarrió and Dr. G. Moreno-Bueno for helpful suggestions and comments, Dr. J.A. García-Sanz for his training and advice with the polysome analysis by sucrose gradient centrifugation, Dr. M. Díaz-Guerra and Oscar Gómez for reagents and help for the calpain experiments, and the mentioned colleagues who kindly supplied us with the different cells lines. During the course of this work several undergraduate students collaborated with us as part of their training courses: Ana Coelho, Leyre Larzabal, Alvaro Martínez, Irene Platas, Pedro Ramos, and Beatriz Vindel. This work was supported by grant SAF2007-63821 from the Spanish Ministry of Education and Science.

\section{References}

Breiteneder-Geleff S, Matsui K, Soleiman A, Meraner P, Poczewski H, Kalt R, et al. . Podoplanin, novel 43-kd membrane protein of glomerular epithelial cells, is down-regulated in puromycin nephrosis. Am J Pathol 1997;151:1141-52.

Breiteneder-Geleff S, Soleiman A, Kowalski H, Horvat R, Amann G, Kriehuber E, et al. . Angiosarcomas express mixed endothelial phenotypes of blood and lymphatic capillaries: podoplanin as a specific marker for lymphatic endothelium. Am J Pathol 1999;154:385-94.

Chen F, Wilusz J. Auxiliary downstream elements are required for efficient polyadenylation of mammalian pre-mRNAs. Nucl Acids Res 1998;26:2891-98.

Chomczynski P, Mackey K. One-hour downward capillary blotting of RNA at neutral pH. Anal Biochem 1994;221:303-5.

Chu AY, Litzky LA, Pasha TL, Acs G, Zhang PJ. Utility of D2-40, a novel mesothelial marker, in the diagnosis of malignant mesothelioma. Mod Pathol 2005;18:105- 
10.

Church GM, Gilbert W. Genomic sequencing. Proc Natl Acad Sci U S A 1984;81:1991-5.

del Prete MJ, Vernal R, Dolznig H, Mullner EW, Garcia-Sanz JA. Isolation of polysome-bound mRNA from solid tissues amenable for RT-PCR and profiling experiments. RNA 2007;13:414-21.

Figueiredo-Pereira ME, Banik N, Wilk S. Comparison of the Effect of Calpain Inhibitors on Two Extralysosomal Proteinases: The Multicatalytic Proteinase Complex and m-Calpain. Journal of Neurochemistry 1994;62:1989-94.

Franco SJ, Huttenlocher A. Regulating cell migration: calpains make the cut. J Cell Sci 2005;118:3829-38.

Gandarillas A, Scholl FG, Benito N, Gamallo C, Quintanilla M. Induction of PA2.26, a cell-surface antigen expressed by active fibroblasts, in mouse epidermal keratinocytes during carcinogenesis. Mol Carcinog 1997;20:10-8.

Hall-Pogar T, Zhang H, Tian B, Lutz CS. Alternative polyadenylation of cyclooxygenase-2. Nucleic Acids Res 2005;33:2565-79.

Hantusch B, Kalt R, Krieger S, Puri C, Kerjaschki D. Sp1/Sp3 and DNA-methylation contribute to basal transcriptional activation of human podoplanin in MG63 versus Saos-2 osteoblastic cells. BMC Mol Biol 2007;8:20.

Hu J, Lutz CS, Wilusz J, Tian B. Bioinformatic identification of candidate cisregulatory elements involved in human mRNA polyadenylation. Rna 2005;11:1485-93.

Kato Y, Fujita N, Kunita A, Sato S, Kaneko M, Osawa M, et al. . Molecular Identification of Aggrus/T1 $\alpha$ as a Platelet Aggregation-inducing Factor Expressed in Colorectal Tumors. J Biol Chem 2003;278:51599-605. 
Kato Y, Kaneko M, Sata M, Fujita N, Tsuruo T, Osawa M. Enhanced expression of Aggrus (T1 $\alpha$ /podoplanin), a platelet-aggregation-inducing factor in lung squamous cell carcinoma. Tumour Biol 2005;26:195-200.

Kato Y, Sasagawa I, Kaneko M, Osawa M, Fujita N, Tsuruo T. Aggrus: a diagnostic marker that distinguishes seminoma from embryonal carcinoma in testicular germ cell tumors. Oncogene 2004;23:8552-6.

Kriehuber E, Breiteneder-Geleff S, Groeger M, Soleiman A, Schoppmann SF, Stingl $\mathrm{G}$, et al. . Isolation and characterization of dermal lymphatic and blood endothelial cells reveal stable and functionally specialized cell lineages. J Exp Med 2001;194:797-808.

Lebart MC, Benyamin Y. Calpain involvement in the remodeling of cytoskeletal anchorage complexes. Febs J 2006;273:3415-26.

Lee JY, Yeh I, Park JY, Tian B. PolyA_DB 2: mRNA polyadenylation sites in vertebrate genes. Nucleic Acids Res 2007;35:D165-8.

Ma T, Yang B, Matthay MA, Verkman AS. Evidence against a role of mouse, rat, and two cloned human t1 $\alpha$ isoforms as a water channel or a regulator of aquaporintype water channels. Am J Respir Cell Mol Biol 1998;19:143-9.

Marks A, Sutherland DR, Bailey D, Iglesias J, Law J, Lei M, et al. . Characterization and distribution of an oncofetal antigen (M2A antigen) expressed on testicular germ cell tumours. Br J Cancer 1999;80:569-78.

Martín-Villar E, Megias D, Castel S, Yurrita MM, Vilaro S, Quintanilla M. Podoplanin binds ERM proteins to activate RhoA and promote epithelial-mesenchymal transition. J Cell Sci 2006;119:4541-53.

Martin-Villar E, Scholl FG, Gamallo C, Yurrita MM, Munoz-Guerra M, Cruces J, et al. . Characterization of human PA2.26 antigen (T1alpha-2, podoplanin), a small 
membrane mucin induced in oral squamous cell carcinomas. Int J Cancer 2005;113:899-910.

Massague J, Seoane J, Wotton D. Smad transcription factors. Genes Dev $2005 ; 19: 2783-810$.

Moon RT. Wnt//-Catenin Pathway. Sci STKE 2005;2005:cm1.

Natalizio BJ, Muniz LC, Arhin GK, Wilusz J, Lutz CS. Upstream Elements Present in the 3'-Untranslated Region of Collagen Genes Influence the Processing Efficiency of Overlapping Polyadenylation Signals. J Biol Chem 2002;277:42733-40.

Pradet-Balade B, Boulme F, Beug H, Mullner EW, Garcia-Sanz JA. Translation control: bridging the gap between genomics and proteomics? Trends Biochem Sci 2001;26:225-9.

Qin X, Ahn S, Speed TP, Rubin GM. Global analyses of mRNA translational control during early Drosophila embryogenesis. Genome Biol 2007;8:R63.

Ramirez MI, Millien G, Hinds A, Cao Y, Seldin DC, Williams MC. T1 $\alpha$, a lung type I cell differentiation gene, is required for normal lung cell proliferation and alveolus formation at birth. Dev Biol 2003;256:61-72.

Rechsteiner M, Rogers SW. PEST sequences and regulation by proteolysis. Trends Biochem Sci 1996;21:267-71.

Rishi AK, Joyce-Brady M, Fisher J, Dobbs LG, Floros J, VanderSpek J, et al. . Cloning, characterization, and development expression of a rat lung alveolar type I cell gene in embryonic endodermal and neural derivatives. Dev Biol $1995 ; 167: 294-306$.

Sambrook J, Russell DW (2001). Molecular Cloning, a laboratory manual, 3rd edition, (Editor ed.). Cold Spring Harbor, New York: Cold Spring Harbor 
Laboratory Press.

Sandelin A, Carninci P, Lenhard B, Ponjavic J, Hayashizaki Y, Hume DA. Mammalian RNA polymerase II core promoters: insights from genome-wide studies. Nat Rev Genet 2007;8:424-36.

Schacht V, Dadras SS, Johnson LA, Jackson DG, Hong YK, Detmar M. Up-regulation of the lymphatic marker podoplanin, a mucin-type transmembrane glycoprotein, in human squamous cell carcinomas and germ cell tumors. Am J Pathol 2005;166:913-21.

Schacht V, Ramirez MI, Hong YK, Hirakawa S, Feng D, Harvey N, et al. . T1 $\alpha /$ podoplanin deficiency disrupts normal lymphatic vasculature formation and causes lymphedema. Embo J 2003;22:3546-56.

Schek N, Cooke C, Alwine JC. Definition of the upstream efficiency element of the simian virus 40 late polyadenylation signal by using in vitro analyses. Mol Cell Biol 1992;12:5386-93.

Scholl FG, Gamallo C, Quintanilla M. Ectopic expression of PA2.26 antigen in epidermal keratinocytes leads to destabilization of adherens junctions and malignant progression. Lab Invest 2000;80:1749-59.

Scholl FG, Gamallo C, Vilaró S, Quintanilla M. Identification of PA2.26 antigen as a novel cell-surface mucin-type glycoprotein that induces plasma membrane extensions and increased motility in keratinocytes. J Cell Sci 1999;112 ( Pt 24):4601-13.

Takeda JI, Suzuki Y, Sakate R, Sato Y, Seki M, Irie T, et al. . Low conservation and species-specific evolution of alternative splicing in humans and mice: comparative genomics analysis using well-annotated full-length cDNAs. Nucleic Acids Res 2008;36:6386-95. 
Tompa P, Buzder-Lantos P, Tantos A, Farkas A, Szilagyi A, Banoczi Z, et al. . On the sequential determinants of calpain cleavage. J Biol Chem 2004;279:20775-85.

Tsubuki S, Saito Y, Tomioka M, Ito H, Kawashima S. Differential inhibition of calpain and proteasome activities by peptidyl aldehydes of di-leucine and tri-leucine. $\mathrm{J}$ Biochem 1996;119:572-6.

Wicki A, Christofori G. The potential role of podoplanin in tumour invasion. Br J Cancer 2007;96:1-5.

Wicki A, Lehembre F, Wick N, Hantusch B, Kerjaschki D, Christofori G. Tumor invasion in the absence of epithelial-mesenchymal transition: podoplaninmediated remodeling of the actin cytoskeleton. Cancer Cell 2006;9:261-72.

Xi L, Feber A, Gupta V, Wu M, Bergemann AD, Landreneau RJ, et al. . Whole genome exon arrays identify differential expression of alternatively spliced, cancer-related genes in lung cancer. Nucleic Acids Res 2008.

Zimmer G, Klenk HD, Herrler G. Identification of a 40-kDa cell surface sialoglycoprotein with the characteristics of a major influenza $\mathrm{C}$ virus receptor in a Madin-Darby canine kidney cell line. J Biol Chem 1995;270:17815-22.

Zimmer G, Oeffner F, Von Messling V, Tschernig T, Groness HJ, Klenk HD, et al. . Cloning and characterization of gp36, a human mucin-type glycoprotein preferentially expressed in vascular endothelium. Biochem J 1999;341 ( Pt 2):277-84.

\section{FIG. LEGENDS}

Fig. 1. Analysis of podoplanin mRNA and protein expression in human cell lines. Podoplanin mRNA expression was monitored by RT-PCR $(A)$ or Northern blot analysis (B). GAPDH and were used as controls for the amount of RNA and $\beta$-actin for the 
amount of protein. $C$, Western blot analysis using antibody Ab1 (see Materials and methods). HeLa cells stably transfected with PDPN cDNA (HeLa-PDPN) were used as a positive control. Also, $\alpha$-tubulin was used as a control for the amount of protein loaded in the gel. $D$, Confocal immunofluorescence detection of podoplanin in KLE cells. Horizontal (xy) optical sections are shown in the upper panel and inset (apical domain). The lower panel shows a section in a vertical (xz) optical plane.

Fig. 2. Analysis of transcriptional regulation of $P D P N$ expression. $A$, Determination of the transcriptional start site in NCCIT cells. Primer extension of NCCIT RNA was carried out as described in Materials and methods. The Fig. shows the autoradiography of the gel. Lane 1, elongation reaction made in the presence of $10 \% \mathrm{DMSO}$ for $1 \mathrm{~h}$ at $42^{\circ} \mathrm{C}$; lane 2, the same incubation without DMSO; lane 3, incubation at $60^{\circ} \mathrm{C}$, without DMSO; lane 4, no RNA added. A, C, G and T are sequencing reactions made with the same ${ }^{32} \mathrm{P}$-labelled deoxyoligonucleotide using as template a plasmid with $2 \mathrm{~kb}$ of $5^{\prime}$ upstream sequence from the initiator ATG. $B$, Alternate polyadenylation signals account for the expression of 0.9 and $2.7 \mathrm{~kb}$ mRNAs. In the upper panel a diagram of the $P D P N$ transcript is shown, containing the open reading frame as well as the two polyadenylation signals and the Alu sequence. The locations of the probes used for the Northern analysis and the estimated sizes of the two mRNAs are also shown in the upper panel, as well as the expected sizes of the two mRNAs. The lower panel shows the hybridization with probes A and B of total RNA from the indicated cell lines. $C$, Sequence surrounding the proximal (upper row) and distal (lower row) polyadenylation sites. Numbers on the left of the sequences are coordinates from

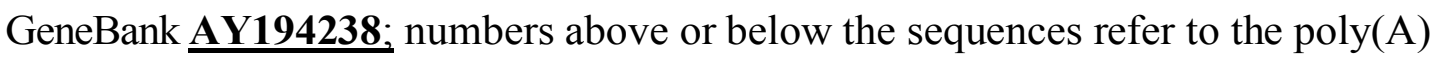
addition site, indicated by vertical arrows. Bold underline shows the binding sites for CstF; double underline and italics shows the AUE in the proximal polyadenylation 
region.

Fig. 3. Differential splicing in the $P D P N$ gene. $A$, Diagram showing the sequence boundaries of exons 5 and 6 (capital letters) and intron 5 (small letters). Double and single underlines show the two possible donor sites. $B$, ESTs spanning the splicing region were obtained from Unigene (http://www.ncbi.nlm.nih.gov/UniGene/ build \#208) or detected by 3'-RACE using lung or NCCIT RNA. C, Amino acid sequence of podoplanin cytoplasmic tail from different vertebrates.

Fig. 4. Polysome analysis of HEK293T cells. Gradients and extracts were prepared as described in Materials and methods. Gradients were fractionated from the top; the "free" fractions correspond to ribonucleoproteins, 40S, 60S subunits and single ribosomes; "bound" refer to polysome-containing fractions. A, methylene blue staining of the membrane; B, autoradiography. Small arrows in panel point to $28 \mathrm{~S}$ (upper) and 18S (lower) rRNAs, respectively; C, quantification of the hybridisation shown in B. Open circles, $0.9 \mathrm{~kb}$ mRNA; filled circles, $2.7 \mathrm{~kb}$ mRNA; dashed line, ratio 28S/18S calculated from the methylene blue staining.

Fig. 5. Inhibition of calpain proteolytic activity stabilises podoplanin expression. $A$, Western blot analysis of podoplanin expression in HN30 cells after treatment with the indicated proteasome and/or calpain inhibitors. Cells were treated with the inhibitors or vehicle (DMSO) as described in Materials and methods. Values below the upper blot represent podoplanin expression levels relative to $\beta$-actin levels quantified by densitometric analysis. $B$, Comparison of the levels of podoplanin accumulated after treatment of HN30, HT1080 and SCC13 cell lines with calpeptin. Podoplanin levels relative to $\alpha$-tubulin levels were quantified by densitometry. Values in the table at the bottom were calculated by subtracting the levels of podoplanin synthesized in basal conditions (DMSO) from those obtained after treatment with 
calpeptin. An arbitrary value of 100 was given to $\mathrm{HN} 30$. $C$, In vitro digestion of NCCIT and MDCK-PDPN-EGFP extracts with calpain-1. Numbers above the upper blots represent the units of calpain-1 in the reaction. $\beta$-actin was used as a control for the amount of protein. 
Table 1. Expression of podoplanin mRNA and protein in human cell lines

\begin{tabular}{|c|c|c|c|}
\hline Origin & Cell line & mRNA & Protein \\
\hline \multicolumn{4}{|l|}{ Noncancerous } \\
\hline Epidermal keratinocytes & $\mathrm{HaCaT}$ & -- & -- \\
\hline Embryonic Kidney & HEK-293T & + & $+/-$ \\
\hline \multirow[t]{2}{*}{ Mammary epithelium } & MCF10A & + & $+/-$ \\
\hline & HBL100 & - & -- \\
\hline Lung primary fibroblasts & NP & + & -- \\
\hline \multicolumn{4}{|l|}{ Cancerous } \\
\hline \multirow[t]{4}{*}{ Colon carcinoma } & SW480 & -- & -- \\
\hline & LOVO & -- & -- \\
\hline & HT29-P & -- & -- \\
\hline & HT29-P-LMN & -- & -- \\
\hline \multirow[t]{5}{*}{ Pancreatic carcinoma } & IMIMPC-1 & -- & -- \\
\hline & IMIMPC-2 & -- & -- \\
\hline & PANC-1 & -- & -- \\
\hline & SK-PC-1 & -- & -- \\
\hline & RWP-1 & -- & -- \\
\hline \multirow[t]{5}{*}{ Ductal breast carcinoma } & MCF-7 & -- & -- \\
\hline & MDA-MB-231 & -- & -- \\
\hline & MDA-MB-435 & -- & -- \\
\hline & ВТ-549 & -- & -- \\
\hline & CAMA1 & -- & -- \\
\hline \multirow[t]{2}{*}{ Ovarian carcinoma } & NIHOVCAR-3 & -- & -- \\
\hline & SKOV3 & -- & -- \\
\hline \multirow[t]{5}{*}{ Endometrial carcinoma } & KLE & + & + \\
\hline & HEC 1B & -- & -- \\
\hline & $\mathrm{AN} 3 \mathrm{Ca}$ & -- & -- \\
\hline & HEC-265 & -- & -- \\
\hline & Ishikawa & -- & -- \\
\hline \multirow[t]{2}{*}{ Endometrial carcinosarcoma } & SK-UT1 & + & $+/-$ \\
\hline & SK-UT1B & + & $+/-$ \\
\hline \multicolumn{4}{|l|}{ Squamous cell carcinoma } \\
\hline Skin & $\mathrm{SCC} 13$ & + & $+/-$ \\
\hline \multirow[t]{5}{*}{ Oral cavity } & HN19 & + & -- \\
\hline & HN30 & + & -- \\
\hline & SCC9 & + & -- \\
\hline & $\mathrm{FaDu}$ & + & $+/-$ \\
\hline & Detroit 562 & + & $+/-$ \\
\hline Cervix & $\mathrm{HeLa}$ & -- & -- \\
\hline Prostate carcinoma (brain metastasis) & DU-145 & + & $+/-$ \\
\hline \multirow[t]{2}{*}{ Embryonal carcinoma } & NCCIT & + & ++ \\
\hline & NTERA-2 & + & + \\
\hline \multicolumn{4}{|l|}{ Sarcoma } \\
\hline Fibro- & HT1080 & + & $+/-$ \\
\hline Osteo- & SAOS-2 & + & -- \\
\hline \multirow{2}{*}{ Neuroblastoma } & SK-N-MC & -- & -- \\
\hline & SH-SY5Y & -- & -- \\
\hline
\end{tabular}


\pm , indicates low level or non consistent results between replicates. mRNA and protein were determined by RT-PCR and Western immunoblotting, respectively. For Western blot studies two distinct podoplanin antibodies that recognize the protein ectodomain were used, as described in Materials and methods. 
Reviewer \#1:

1) As explained in the text, we used calpains inhibitors because the proteasome inhibitors we used in first place were also inhibitors of calpains, and we wanted to be sure about the proteolytic system involved in podoplanin degradation. Although the reviewer states that podoplanin is not degraded by calpains, our results in Fig. $5 \mathrm{C}$ show, on the contrary, that podoplanin is indeed a direct substrate of this family of proteases.

2) Discussion about the up-regulation of podoplanin after treatment with calpains inhibitors. We think that the phenomenon we see is not up-regulation, but stabilization of the protein. In the last paragraphs of the manuscript we discuss the framework in which podoplanin is proteolyzed by calpain, in a process necessary to build up and dismantle multi-molecular protein complexes needed to fulfil the dynamics of actin assembly and disassembly needed in cell motility.

Reviewer \#2

1) We have changed Fig. 1 in a way that, first, uses the same cell lines for Northern and Western blot analysis, including the cell lines requested by the reviewer, and second, we have arranged them in the same order as they appear in Table 1.

2) We have had great difficulties with the polysomal gradients for HN30 cells.

These cells express very low levels of podoplanin mRNA and even though all the procedures were done in the presence of several RNAse inhibitors, is was difficult to obtain publication-quality gradients. So we decided to do gradients for other podoplanin-expressing cells (NCCIT, HEK293T and HT1080) in addition to HN30. In all cases we got $P D P N$ mRNAs in the polysome fractions, so weshow here the HEK293T results as an example.

3) The experiment suggested by the reviewer was actually done, However HEK293T cells did not accumulate podoplanin protein when treated with calpeptin (or lactacystin). This result suggest that other mechanisms may be relevant in this cell type.

In connection with points 2 and 3, we are aware (and we mention it at the end of the manuscript) of the different behaviour of distinct cell types in relation with the regulatory processes we are describing, namely differences in amount of mRNA, or protein or response to the treatments. This is an interesting subject, but we think is out of the scope of this manuscript, that addresses more specifically the several levels of regulation of podoplanin expression. 
4) As suggested by the reviewer, we have performed experiments in order to demonstrate that podoplanin is a direct substrate of calpain (Fig. 5C)

5) As mentioned in the response to reviewer \#1, we have discussed more in depth the framework in which podoplanin could be regulated by calpains.

Minor comments (although pages and lanes do not necessarily coincide now):

Page 7, lane 13: was essentially done as described. Corrected Page 9, lane 22: ..., there was a good correlation between the results...Corrected Page 11, lane 10: add some remarks why you used lung RNA. In the manuscript we state that podoplanin is a protein found in lung; furthermore, the availability of this material in the Tumour Tissue Bank was also an important reason to use lung tissue, although we think is not so important as to mention it explicitly in the manuscript

Page 12, lane 12f: discuss more concise the concluding remarks of this section. What's the point? Paragraph changed

Page 12, lane 16: rephrase "the same splicing sequences in donor/acceptor sites." paragraph changed

Page 12, lane 12/13: write phenylalanine and tyrosine instead of F and Y Corrected Page 12, lane 22: .that another rodent has tyrosine. Corrected

Page 13, lane 1: what is serine-161? If you number the amino acids, do that as well for the F-160 and Y-159. Why do you think that Ser-161 is important? Discuss this point. Paragraph changed

page 13, lane 12: Rephrase the sentence summarizing the polysome fractionation results. Possibly then start a new paragraph with more clear introductory words.

\section{Paragraph changed}

Page 13, lane 14: rephrase to ".with the proteasome inhibitors ALLN and MG132 that.and with the specific..". Describe more detailed the mode of action of ALLN and MG132 (plus literature). Paragraph changed

Page 13, lane 21: ..as a control of proteasomal degradation activity (Fig. 5A).

Corrected

Figure legends:

Fig. 4, lane 3: explain RNP Corrected

Fig. 4, lane 5: .in panel B point to 28S Corrected

Reviewer \#3

1) The reviewer asks for a more extensive discussion of the possible biological relevance of the findings. With regard of the $\Delta \mathrm{YS}$ isoform we are starting now to study its properties in well known aspects of podoplanin function (as cell motility and epithelial-mesenchimal transition). However our findings are very preliminary to make any statement in a publication. Regarding to the rationale of podoplanin calpain-mediated proteolysis, we have discussed it in the response to reviewer \#1. With respect to minor comments,

- $\quad$ Page 3, Introduction: "...glycoprotein expressed ON the surface of tumour cells (...). The interest IN this membrane glycoprotein..." Corrected 
- $\quad$ Page 6, Materials and Methods, paragraph 2.2: instead of giving antibody dilutions (from unknown original concentrations), it would be more useful to know the actual concentrations of the antibodies used. We have included concentrations whenever possible. However,Ab1 was produced by us and is not purified.

- $\quad$ Page 7, Materials and Methods, paragraph 2.4: some more details on the labelling with polynucleotide kinase would be desirable. Paragraph added - $\quad$ Page 11, Results and Discussion, paragraph 3.2: typo "mRNA spePcies" (center of page) Corrected

- $\quad$ Page 13, Results and Discussion, paragraph 3.4: two references are still in preliminary format " $\{\ldots \# 727 \ldots \# 728 \ldots\}$ " Corrected

- $\quad$ Page 13, Results and Discussion, paragraph 3.4: typo "stabilYsed" (bottom of page) Corrected

- $\quad$ Page 21, Figure Legends, Fig. 2: vertical arrows are mentioned which are not present in the figure. The arrows are present in the diagram, although perhaps not big enough, as they are of the same size of the other letters used. However, its place is also marked by a " $+\mathrm{A}$ ", so we think it is not necessary to make them larger.

- $\quad$ Page 21, Figure Legends, Fig. 4: No indication about the difference between empty and filled circles in panel $\mathrm{C}$ of the figure. Corrected 
Table 1. Expression of podoplanin mRNA and protein in human cell lines

\begin{tabular}{|c|c|c|c|}
\hline Origin & Cell line & mRNA & Protein \\
\hline \multicolumn{4}{|l|}{ Noncancerous } \\
\hline Epidermal keratinocytes & $\mathrm{HaCaT}$ & -- & -- \\
\hline Embryonic Kidney & HEK-293T & + & $+/-$ \\
\hline \multirow[t]{2}{*}{ Mammary epithelium } & MCF10A & + & $+/-$ \\
\hline & HBL100 & - & -- \\
\hline Lung primary fibroblasts & NP & + & -- \\
\hline \multicolumn{4}{|l|}{ Cancerous } \\
\hline \multirow[t]{4}{*}{ Colon carcinoma } & SW480 & -- & -- \\
\hline & LOVO & -- & -- \\
\hline & HT29-P & -- & -- \\
\hline & HT29-P-LMN & -- & -- \\
\hline \multirow[t]{5}{*}{ Pancreatic carcinoma } & IMIMPC-1 & -- & -- \\
\hline & IMIMPC-2 & -- & -- \\
\hline & PANC-1 & -- & -- \\
\hline & SK-PC-1 & -- & -- \\
\hline & RWP-1 & -- & -- \\
\hline \multirow[t]{5}{*}{ Ductal breast carcinoma } & MCF-7 & -- & -- \\
\hline & MDA-MB-231 & -- & -- \\
\hline & MDA-MB-435 & -- & -- \\
\hline & BT-549 & -- & -- \\
\hline & CAMA1 & -- & -- \\
\hline \multirow[t]{2}{*}{ Ovarian carcinoma } & NIHOVCAR-3 & -- & -- \\
\hline & SKOV3 & -- & -- \\
\hline \multirow[t]{5}{*}{ Endometrial carcinoma } & KLE & + & + \\
\hline & HEC 1B & -- & -- \\
\hline & AN3Ca & -- & -- \\
\hline & HEC-265 & -- & -- \\
\hline & Ishikawa & -- & -- \\
\hline \multirow[t]{2}{*}{ Endometrial carcinosarcoma } & SK-UT1 & + & $+/-$ \\
\hline & SK-UT1B & + & $+/-$ \\
\hline \multicolumn{4}{|l|}{ Squamous cell carcinoma } \\
\hline Skin & SCC13 & + & $+/-$ \\
\hline \multirow[t]{5}{*}{ Oral cavity } & HN19 & + & -- \\
\hline & HN30 & + & -- \\
\hline & SCC9 & + & -- \\
\hline & $\mathrm{FaDu}$ & + & $+/-$ \\
\hline & Detroit 562 & + & $+/-$ \\
\hline Cervix & HeLa & -- & -- \\
\hline Prostate carcinoma (brain metastasis) & DU-145 & + & $+/-$ \\
\hline \multirow[t]{2}{*}{ Embryonal carcinoma } & NCCIT & + & ++ \\
\hline & NTERA-2 & + & + \\
\hline \multicolumn{4}{|l|}{ Sarcoma } \\
\hline Fibro- & HT1080 & + & $+/-$ \\
\hline Osteo- & SAOS-2 & + & -- \\
\hline \multirow{2}{*}{ Neuroblastoma } & SK-N-MC & -- & -- \\
\hline & SH-SY5Y & -- & -- \\
\hline
\end{tabular}


\pm , indicates low level or non consistent results between replicates. mRNA and protein were determined by RT-PCR and Western immunoblotting, respectively. For Western blot studies two distinct podoplanin antibodies that recognize the protein ectodomain were used, as described in Materials and methods. 

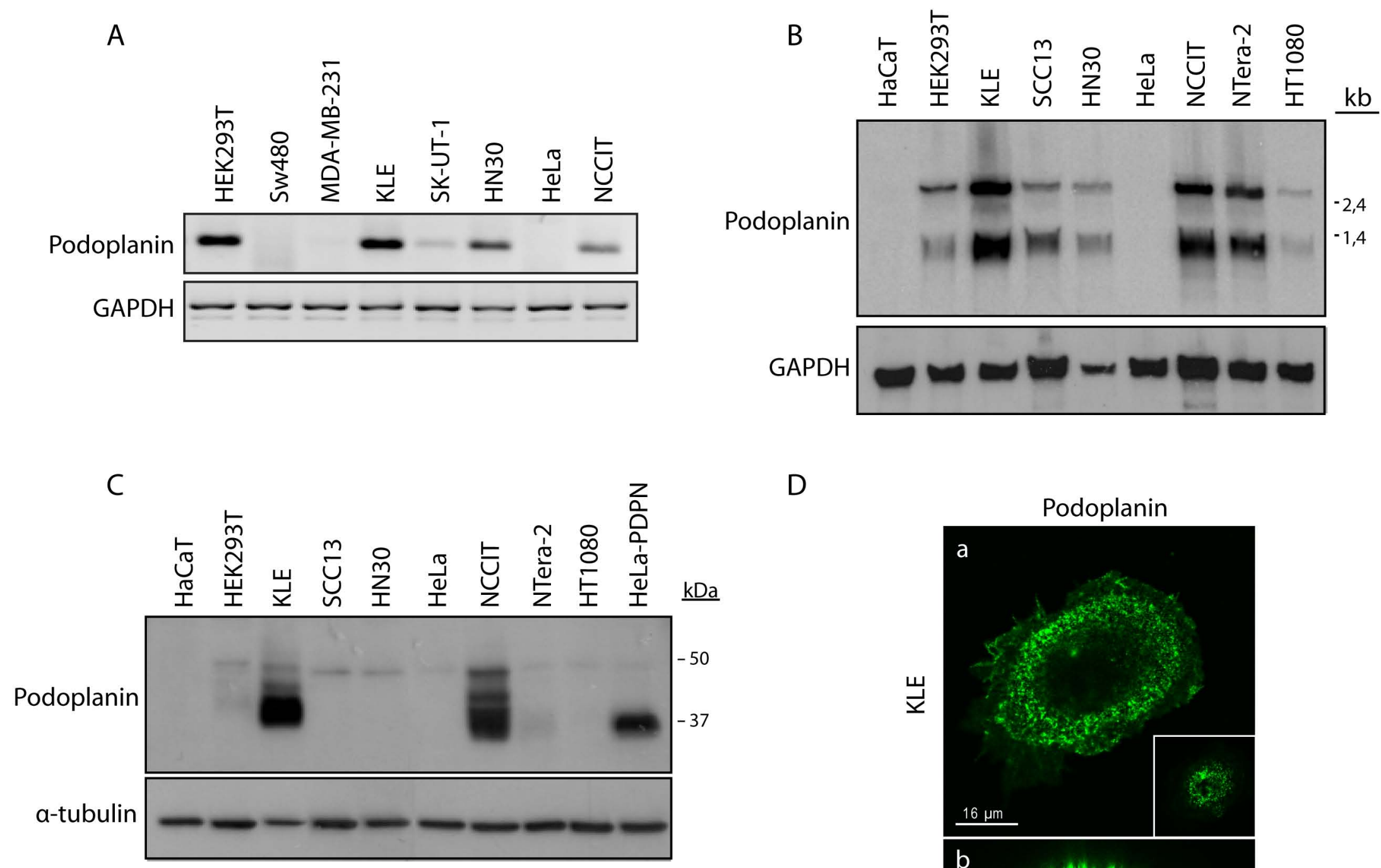

D

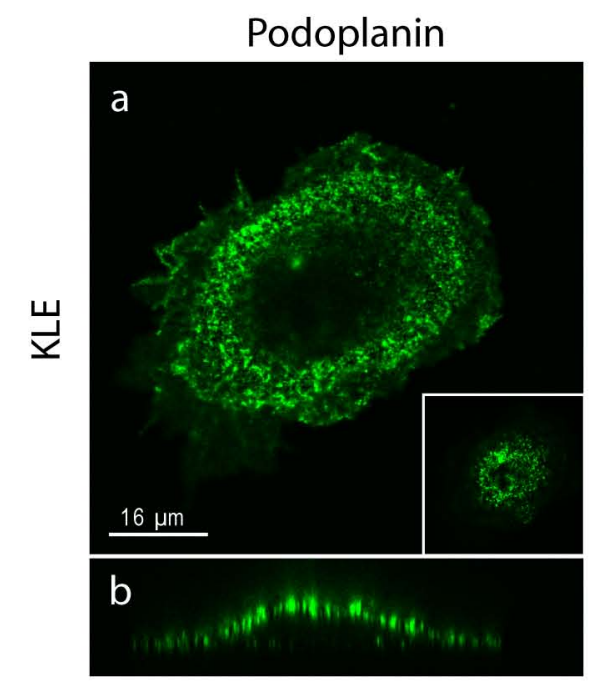

Martín-Villar et al., Figure 1 


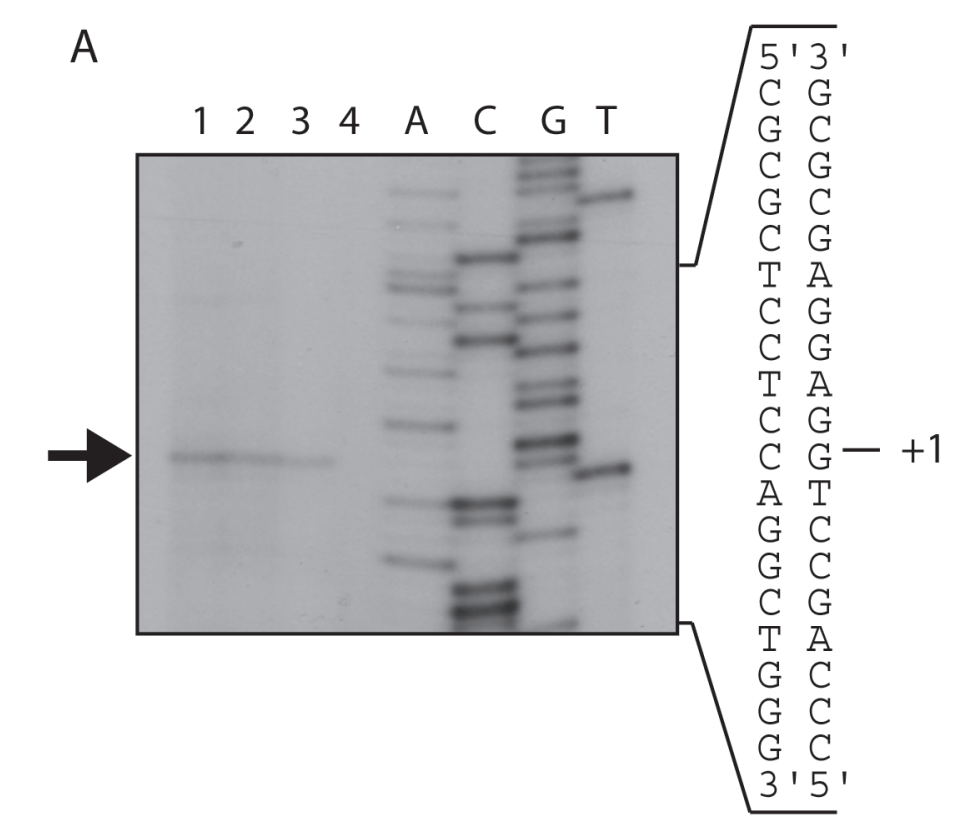

B
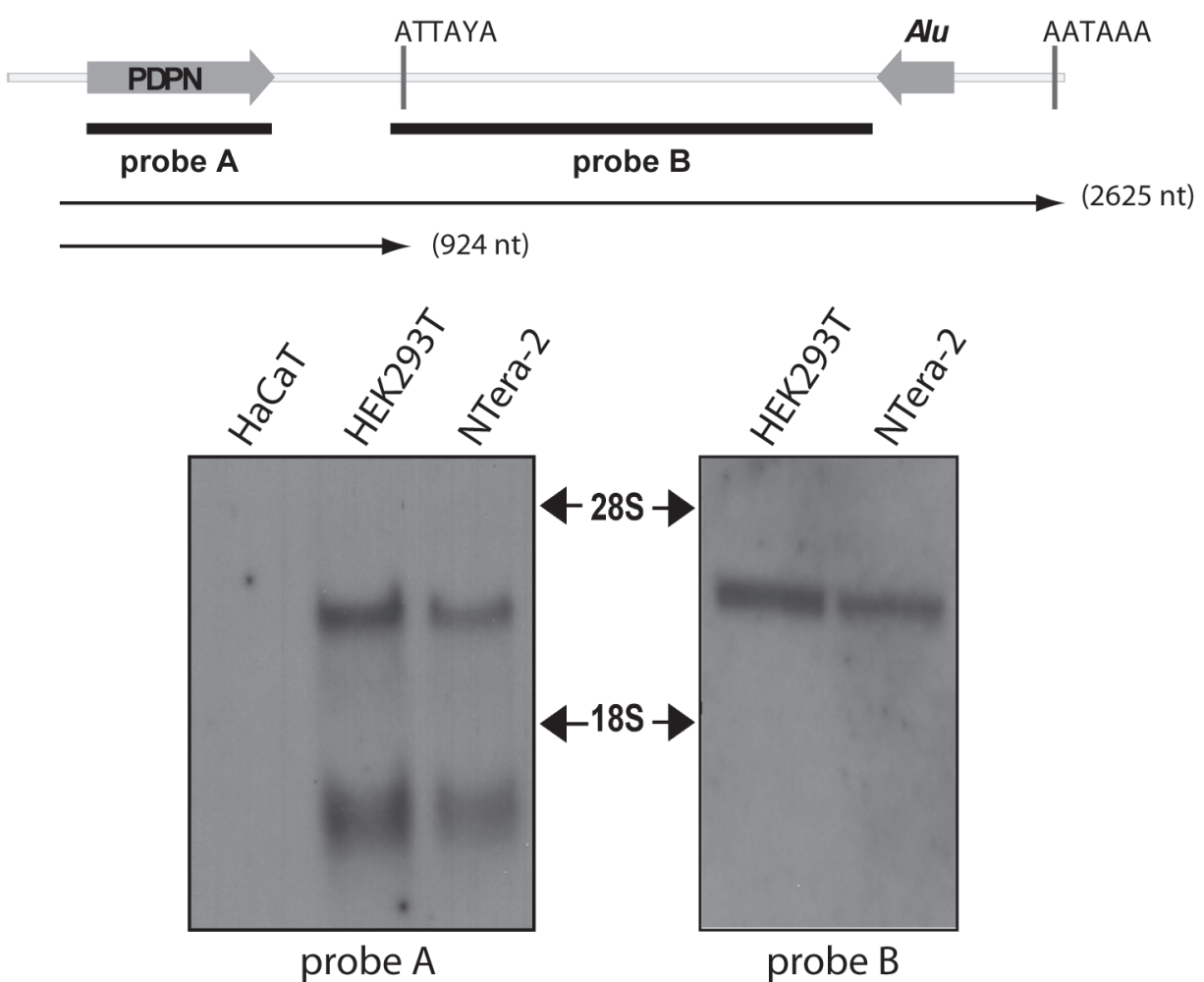

C

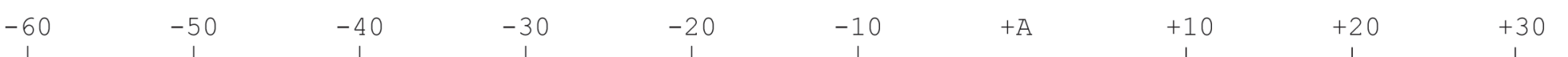

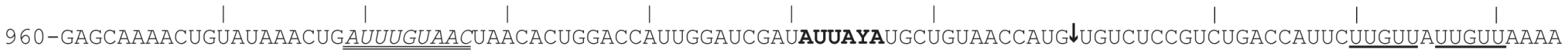
2662-GUUUCUUGGUCACACCUGUGUUGGUGCUCAAUGCAGUGUAGACAUGUUUUCAAAUAAAACAAAUGAUUGUGU $\uparrow$ ACAACAAUGGGUCAGACUUUUGUUGGAAAACACA $\begin{array}{cccccccccc}1 & 1 & 1 & 1 & 1 & 1 & & & 1 & 1 \\ -60 & -50 & -40 & -30 & -20 & -10 & +A & +10 & +20 & +30\end{array}$ 
A

$\frac{\mathrm{R}}{\mathrm{CGA}} \frac{\mathrm{K}}{\mathrm{AAA}} \frac{\mathrm{M}}{\mathrm{ATG}} \frac{\mathrm{S}}{\mathrm{TCG}} \frac{\mathrm{G}}{\mathrm{GGA}} \frac{\mathrm{R}}{\mathrm{AGG}} \frac{\mathrm{Y}}{\mathrm{TAC}} \frac{\mathrm{S}}{\mathrm{TC}}$ gtaa $\ldots . . . \operatorname{ttccag} \overline{\mathrm{G}} \frac{\mathrm{P}}{\mathrm{CCC}} \frac{\star}{\mathrm{TAA}}$

B

\begin{tabular}{|r|c|c|c|}
\hline & YS present & YS absent & Total \\
\hline Human EST database & $59(73 \%)$ & $21(27 \%)$ & 80 \\
\hline Lung & $18(45 \%)$ & $15(55 \%)$ & 33 \\
\hline NCCIT cell line & $3(42 \%)$ & $4(58 \%)$ & 7 \\
\hline
\end{tabular}

Homo sapiens (human)

RKMSGRYSP

Pan troglodites (chimpanze)

RKMSGRYSP

Macaca mulatta (rhesus monkey)

RKMSGRYSP

Bos taurus (cow)

Canis gamiliaris (dog)

Felis catus (cat)

Loxodonta africana (elephant)

RKM-GRYSP

RKMSGRYSP

RKMSGRYSP

Sus scrofa (pig)

Mus musculus (mouse)

RKMSGRYSP

RKMSGRYSP

Rattus norvegicus (rat)

Cricetulus griseus (chinese hamster)

KKISGRFSP

RKISGRFSP

KKISGRYSP

Gallus domesticus (chicken)

RKMSGRYSP

Ambystoma mexicanum (axolotl)

KKMSGRYSP

Danio rerio (zebrafish)

Gasterosteus aculeatus (stickleback)

RRM-GQYSP

Salmo trutta (brown trout)

RRM-GKYSP

Oryzias latipes (Japanese medaka)

Takifugu rubripes (pufferfish)

RRM-GKYSP

RRM-GKYSP

Tetraodon nigroviridis (spotted green pufferfish)

RRM-GKYSP

KRM-GKYSP

\section{Martín-Villar et al., Figure 3}


A

B

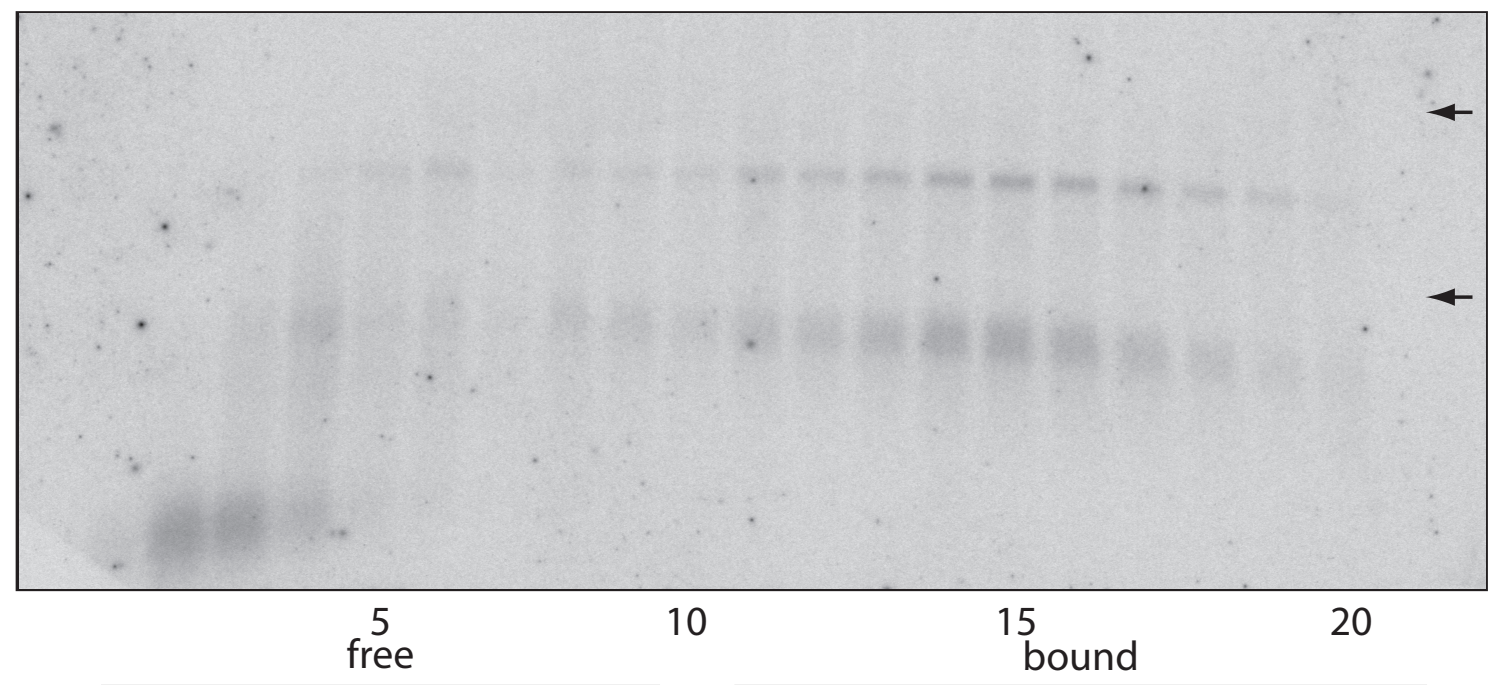

C

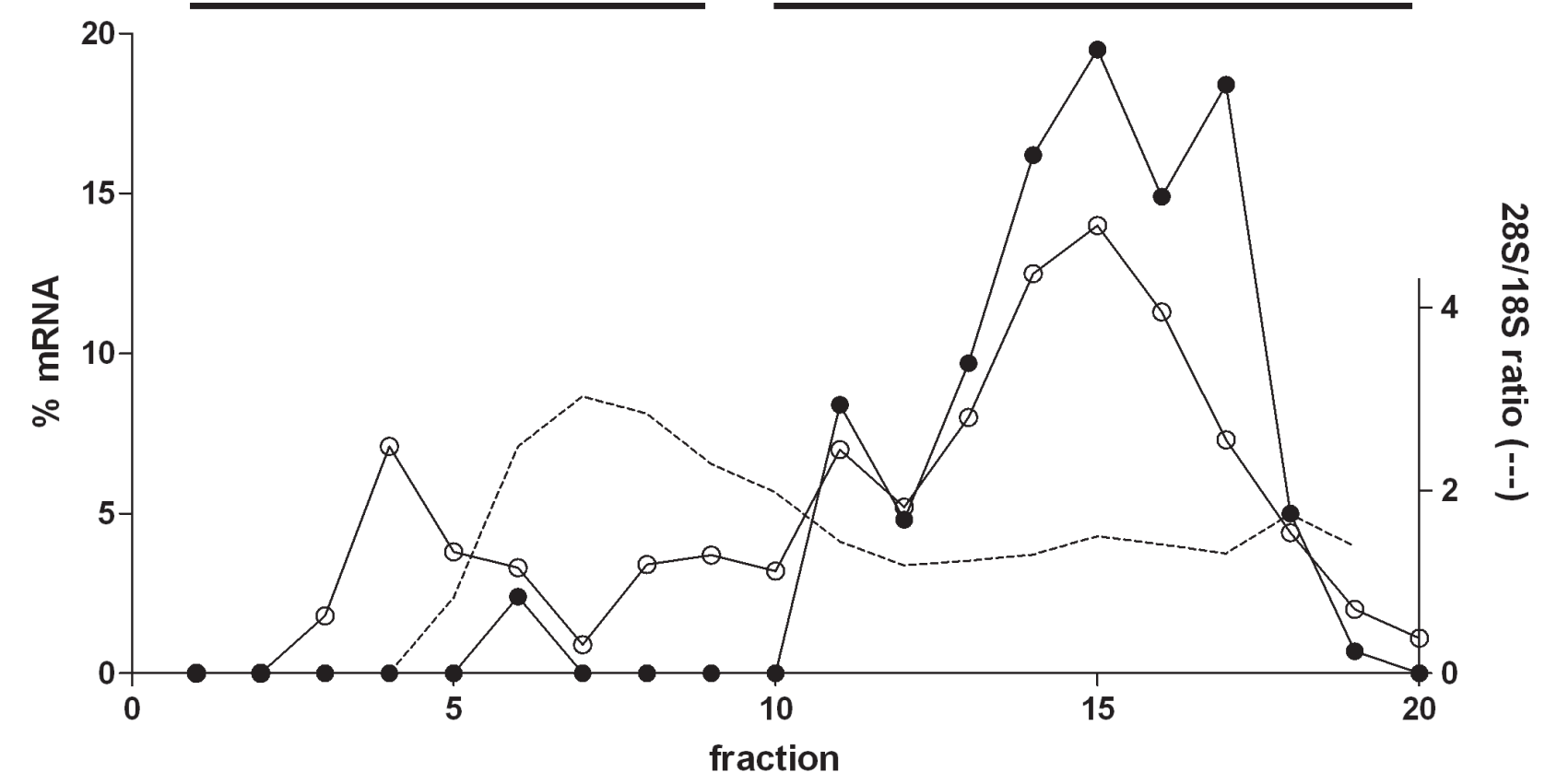

Martín-Villar et al., Figure 4 
A

HN30

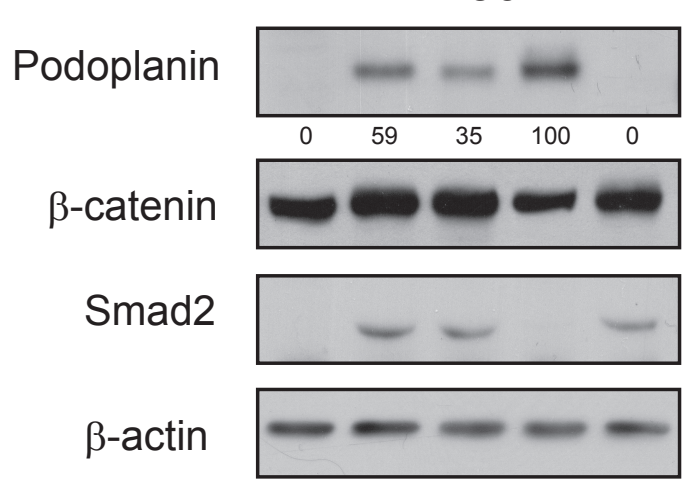

\begin{tabular}{|l|c|c|c|c|c|}
\hline DMSO & + & - & - & - & - \\
\hline ALLN & - & + & - & - & - \\
\hline MG132 & - & - & + & - & - \\
\hline Calpeptin & - & - & - & + & - \\
\hline Lactacystin & - & - & - & - & + \\
\hline
\end{tabular}

B

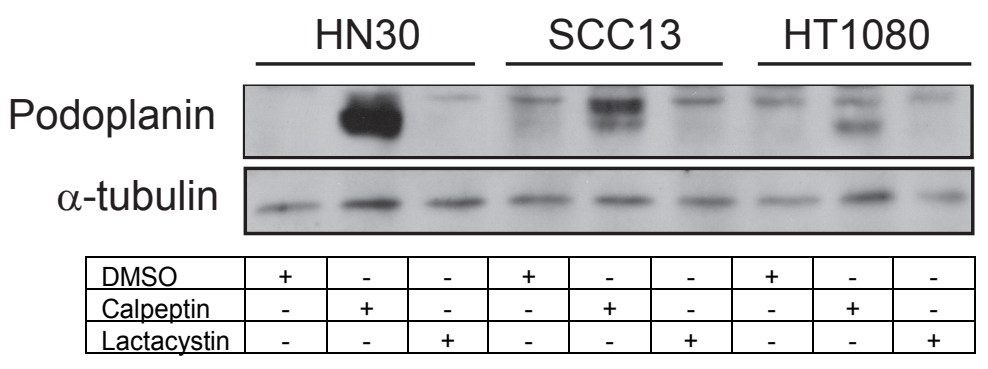

\begin{tabular}{|l|c|}
\hline Cell line & $\begin{array}{c}\text { Calpeptin-induced podoplanin } \\
\text { accumulation } \\
\text { (arbitrary units) }\end{array}$ \\
\hline HN30 & 100 \\
\hline SCC13 & 57 \\
\hline HT1080 & 23 \\
\hline
\end{tabular}

C

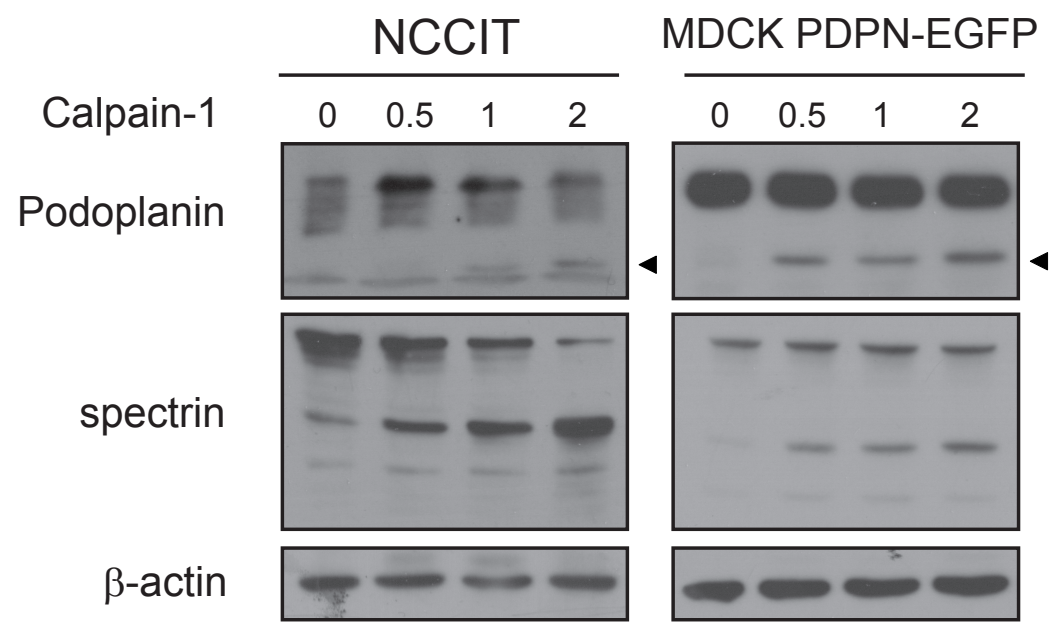

